\title{
The Payment Schedule of Sovereign Debt
}

Working Paper 2017-09

Yan Bai, Seon Tae Kim and Gabriel Mihalache

September 3, 2017

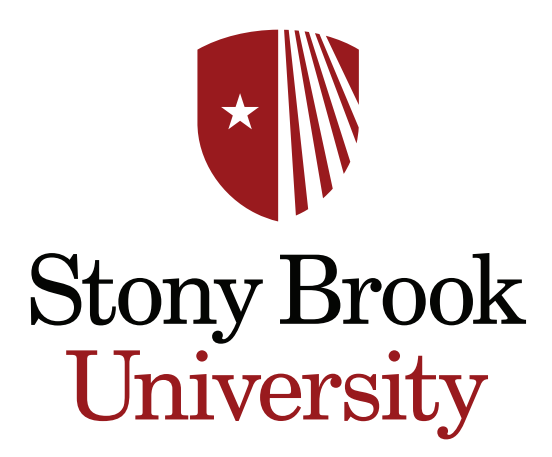




\title{
The Payment Schedule of Sovereign Debt
}

\author{
Yan Bai* Seon Tae Kim ${ }^{\dagger}$ Gabriel Mihalache ${ }^{\ddagger}$
}

September 3, 2017

\begin{abstract}
We document cyclical fluctuations in scheduled payments of newly issued sovereign debt. During recessions, scheduled payments become more back-loaded. Our results provide direct evidence on a key parameter governing the functional form of cash flows in the long-term debt literature.
\end{abstract}

JEL Classification: E32, F34, G15, H63.

Keywords: Sovereign debt; Debt management; Maturity; Payment schedule; Emerging market.

\footnotetext{
*Affiliation: Department of Economics, University of Rochester and NBER. E-mail: yan.bai@rochester.edu

${ }^{\dagger}$ Corresponding Author. Affiliation: Department of Economics, Finance and Accounting, Management School, University of Liverpool. Postal address: Chatham Building, Chatham Street, University of Liverpool, Liverpool, L69 7ZH, UK. Tel: +44-(0)151 794 9878. E-mail: Seon.Kim@liverpool.ac.uk

${ }^{\ddagger}$ Affiliation: Department of Economics, Stony Brook University. E-mail: gabriel.mihalache@stonybrook.edu
} 


\section{Introduction}

Recent research has extended the study of the stock of debt to questions related to its maturity structure, the relative size and timing of payments, for example Rodrik and Velasco (1999), Arellano and Ramanarayanan (2012), Asonuma, Niepelt, and Ranciere (2017). Commonly used measures, like maturity and Macaulay duration, capture only in part the dynamics of payment schedules. Substantially different cash flows, in terms of coupon structure, maturity dates, etc., can exhibit the same duration. In particular, we argue that the cash flow implied by new issuance conveys additional information, hitherto unexploited by standard debt statistics. To address this limitation in existing work, we introduce a parsimonious measure, the average growth rate of scheduled payments, to capture the degree of back-loading of the repayment schedule: the timing and relative size of coupon and principal payments. A higher growth rate of payments induces a more back-loaded schedule, which can greatly help a borrowing country smooth consumption during downturns, since the bulk of obligations will be paid in the future, when the economy is expected to eventually recover.

Using Bloomberg bond data for eleven emerging economies, we investigate the cyclical fluctuations in the scheduled payments of newly issued bonds. Our findings are twofold. First, the growth rate of scheduled payments is higher when spreads are higher. Given that spreads are strongly countercyclical, this implies that scheduled payments are more back-loaded during downturns. Second, the maturity of newly issued bonds is shorter during such periods, confirming the results of Arellano and Ramanarayanan (2012) and Broner, Lorenzoni, and Schmukler (2013). Moreover, our findings about the behavior of payment growth, the main contribution of this paper, are robust to controlling for the maturity. That is, maturity is one of, but not the sole determinant of the growth rate of payments and the shape of the schedule more broadly.

Our results provide direct evidence on a key parameter governing the shape of cash flows in the widely used decaying perpetuity bond structure: Hatchondo and Martinez (2009), Arellano and Ramanarayanan (2012), and Chatterjee and Eyigungor (2012) are only a few of the many recent papers using this functional form restriction, in the quantitative long-term debt literature. This parameter, governing the slope of the schedule, is usually calibrated to match a long-run average measure of duration. We find that its direct data counterpart exhibits substantial and systematic cyclical variation. In this context, our findings are salient to questions related to optimal maturity, debt dilution, and related quantitative-theoretic issues.

\section{Method}

We characterize sovereign debt issuance using three measures: maturity $(T)$, Macaulay duration $(D)$, and the growth rate of payments $(\delta)$. Consider a sovereign country $i$ in period $t$, where time periods $t$ are weeks. That is, we consider weekly issuance as our benchmark, following Broner, Lorenzoni, and Schmukler (2013). Let $c_{t}^{i}(s)$ denote the cash flow-in real U.S. Dollar terms- 
promised by the portfolio issued at period $t$ to be paid $s \in\left\{1,2, \ldots, N_{t}^{i}\right\}$ periods later. $N_{t}^{i}$ refers to the number of periods until the last payment is scheduled. Let $n$ be the number of periods in a year. The benchmark payment frequency is set to one quarter; we set $n=4$, and $s$ counts over the quarters in the lifespan of the bonds. We consider an alternative case, yearly aggregation with $n=1$; results for this specification are qualitatively similar to the benchmark results (See the Online Appendix).

Whenever multiple bonds are issued within a given week, we sum over the cross-section of promised cash flows, within each future period, resulting in a single stream of payments $c_{t}^{i}(s)$, as if the country had issued a single instrument making all the payments scheduled by the actual bonds issued. Such constructed streams are assigned a maturity $T_{t}^{i}$ (in years) given by the average maturity of the actually issued bonds, weighted by each bond's real principal value. We label the promised cash-flow profile $\left\{c_{t}^{i}(s)\right\}_{s=1}^{N_{t}}$ as "payment schedule." To compute the annualized growth rate of payment $\delta_{t}^{i}$, we regress the promised cash flows on the number of years elapsed since the issuance date $t$,

$$
\log c_{t}^{i}(s)=\text { constant }+\delta_{t}^{i} \frac{s}{n}+\epsilon_{t}^{i}(s)
$$

where $\epsilon_{t}^{i}(s)$ is an error term reflecting deviations of the actual schedule from a constant growth rate stream. Table 1 reports country-level, average R-squared statistics for these regressions.

Duration $D_{t}^{i}$ measures the average length of time to payment, weighted by each payment. It is given by

$$
D_{t}^{i}=\sum_{s=1}^{N_{t}^{i}} \frac{c_{t}^{i}(s) R^{-s / n}}{\sum_{s=1}^{N_{t}^{i}}\left\{c_{t}^{i}(s) R^{-s / n}\right\}} \frac{s}{n},
$$

where $R$ denotes the gross annual, real, risk-free rate, which we fix at 3.2 percent, following Arellano and Ramanarayanan (2012). In doing so, we separate movements in quantities (the cash flow) from changes in prices (time-varying discounting). Thus, $D_{t}^{i}$ represents the risk-free version of the Macaulay duration, widely studied in the literature.

Our proposed measure $\delta$ is designed to capture in a parsimonious way rich heterogeneity of bond characteristics in the data: several bonds are sometimes issued within a week, each with different frequency of payments, coupon rates - fixed or variable - currency and maturity. All other things constant, a longer maturity, higher coupon rates, or a higher frequency of payments will tend to "flatten" the payment schedule and reduce the absolute value of $\delta$. In our analysis we document the joint behavior of maturity $(T)$ and the growth rate of scheduled payments $(\delta)$. This can recover additional information, relative to Macaulay duration, which conflates both margins and potentially obscures their distinct dynamics. 


\section{Data}

We study the same set of eleven emerging market sovereigns as Broner, Lorenzoni, and Schmukler (2013). Using the Bloomberg Professional database, we extract information on external debt and construct promised cash flows. In the data, contracts are fairly diverse, employing several coupon types (e.g. fixed rate, zero coupon, step, variable, float), with varying coupon payment frequencies (e.g. annual and semi-annual). Since we focus on issuance, we must address the fact that countries sometimes issue several bonds within the same time period, each with its own rich characteristics, an inherently high-dimensional object. In order to facilitate aggregation of cash flows, both across bonds and over time, we introduce a new statistic: the growth rate of scheduled payments, which captures in a parsimonious way the dynamics of scheduled payments over the lifetime of the bond.

We focus on foreign-currency denominated bonds and exclude bonds either with special features (e.g., collateralized) or with guarantees from international financial institutions, e.g. IMF or World Bank, and foreign governments/banks. ${ }^{1}$ Finally, we exclude zero-coupon bonds ${ }^{2}$ but document the robustness of our findings to this assumption in the Online Appendix.

Since countries issue debt denominated in several currencies, we convert flows to real U.S. Dollars using nominal exchange rates (provided by $I M F$ ) and the U.S. CPI series (from the Bureau of Labor Statistics). We assume that, for a given bond, the exchange rate at the issuance date is used for all future payments ${ }^{3}$ (i.e., martingale process), while the ex-post U.S. CPI is used as a deflator (i.e., perfect foresight). Realized LIBOR rates from EconStats.com are used (i.e., perfect foresight) whenever a bond specifies its coupon rate relative to such a reference rate.

We document key facts about the bond-level issuance data, in relation to the spread series, based on yield curve estimates. These spreads are measured by the differences in the (annualized) yield-to-maturity relative to equivalent U.S. (or German) bonds. We consider spreads for bonds of different maturities: The "three-year" spread is for bonds of maturities up to three years, "nineyear" spread reflects those between six and nine years, and "twelve-year" spread represents all bonds with maturities over nine years. All spreads are weekly series provided by Broner, Lorenzoni, and Schmukler (2013). These are natural choice for a cyclical indicator given the relatively high time frequency of the analysis.

\section{Results}

Table 1 reports the summary statistics. The mean payment growth rate is 19 percent, while the average maturity is about nine years, and the average duration is about seven years. All countries

\footnotetext{
${ }^{1}$ See related discussion in Broner, Lorenzoni, and Schmukler (2013).

${ }^{2}$ Most countries, except for Argentina, Turkey, and Uruguay, did not issue such bonds. In our sample, $40 \%$ of Argentina's bonds are zero-coupon, $84 \%$ for Uruguay and $12 \%$ for Turkey.

${ }^{3}$ This assumption eliminates potentially spurious movements in debt statistics due to ex-post exchange rates dynamics.
} 
issue back-loaded bonds, with positive payment growth, ranging from 11 percent to around 37 percent. We are interested in how emerging markets vary issuance characteristics with the business cycle, as reflected in the 6 -to-9 year interest rate spread, labeled "9-year spread." Table 2 provides correlation coefficients of bond characteristics with such a spread. For all countries except Russia, the maturity is negatively correlated with the spread. Payment schedules are more back-loaded when the interest rate is higher, as reflected in their positive correlation for most countries.

\subsection{Main Results}

We investigate the systemic relationship between payment schedule and spreads. We run panel regressions of maturity, duration, and payment growth, respectively, employing the specification introduced by Broner, Lorenzoni, and Schmukler (2013). The main covariate of interest is the spread and we control for the real exchange rate, terms of trade, and an investment-grade dummy (indicating whether the sovereign bond is rated as investment-grade by credit rating agencies). More specifically, all dependent and explanatory variables are six-month moving averages (using a 26-week rolling window) and demeaned for each country. All explanatory variables are in logs.

The OLS estimates are liable to be biased due either to unobserved country credit quality affecting both the spread and issuance characteristics (i.e., an omitted variable problem) or to the fact that the choice of bond characteristics might impact the spread itself (i.e., a reverse causality problem). As such, we use an instrumental variable (IV) strategy, where we consider two instruments for the spread: first, the US high-yield corporate bond index as in Broner, Lorenzoni, and Schmukler (2013), and second, the spread of Moody's Aaa-rated corporate bonds index. Both of these reflect the risk appetite of investors in the global bond markets and hence likely to be unaffected by the bond supply behavior of countries in our sample. These sovereign debt "demand shifters" allow us to identify supply behavior over debt characteristics.

Table 3 presents our panel regression results ${ }^{4}$, where standard errors are robust to heteroskedasticity and serial correlation (Bartlett kernel with bandwidth of 5, i.e., 4-week lag). Financial conditions are a statistically significant determinants of issuance choice, with a negative coefficient in the regressions of maturity and positive in those for payment growth. Patterns for duration are similar to those for maturity.

Our findings about the cyclical behavior of the growth rate of payments is robust to controlling for maturity: Table 4 reports this case. It shows that maturity is one, but not the sole determinant of the growth rate of scheduled payments.

Our analysis highlights two main results. First, the maturity of bonds shortens during periods of financial distress, consistent with findings in previous work. To the best of own knowledge, our second finding is new to the literature: sovereigns also adjust payment schedules in response to

\footnotetext{
${ }^{4}$ See Table 2 in the Online Appendix for the results for the first-stage regression of the spread on instrumental variables and other control variables.
} 


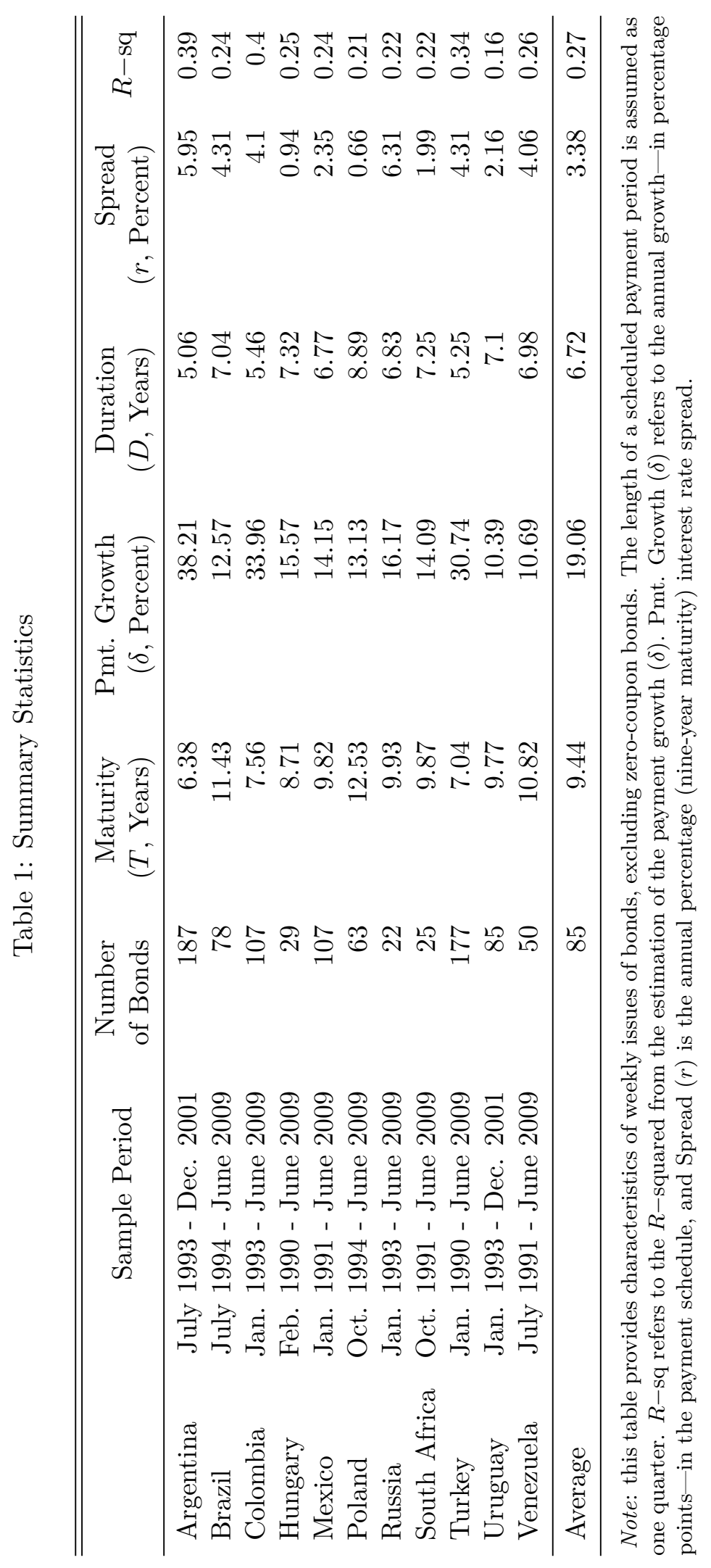


Table 2: Cyclical Behavior of Bond Characteristics

\begin{tabular}{lrrrr}
\hline \multirow{2}{*}{$\begin{array}{l}\text { Corr. with } \\
\text { Spread }\end{array}$} & Maturity & Duration & \multicolumn{2}{c}{ Pmt. Growth $(\delta)$} \\
\cline { 4 - 5 } & $(T)$ & $(D)$ & Quarterly & Yearly \\
\hline Argentina & -0.31 & -0.30 & 0.10 & 0.08 \\
Brazil & -0.48 & -0.55 & 0.52 & 0.45 \\
Colombia & -0.45 & -0.52 & 0.42 & 0.39 \\
Hungary & -0.35 & -0.37 & 0.17 & 0.19 \\
Mexico & -0.23 & -0.30 & 0.23 & 0.23 \\
Poland & -0.28 & -0.34 & 0.30 & 0.32 \\
Russia & 0.32 & 0.25 & -0.14 & -0.01 \\
South Africa & -0.06 & -0.12 & 0.22 & 0.22 \\
Turkey & -0.18 & -0.21 & 0.00 & -0.07 \\
Uruguay & -0.50 & -0.54 & 0.44 & 0.65 \\
Venezuela & -0.12 & -0.18 & 0.20 & 0.16 \\
\hline Average & -0.24 & -0.29 & 0.22 & 0.24 \\
\hline
\end{tabular}

Note: this table provides correlation coefficients of variables with the spread. Spread $(r)$ is the annual percentage (nine-year maturity) interest rate spread. "Quarterly" refers to quarterly aggregation of payment and and "Yearly" refers to yearly aggregation of payment. 


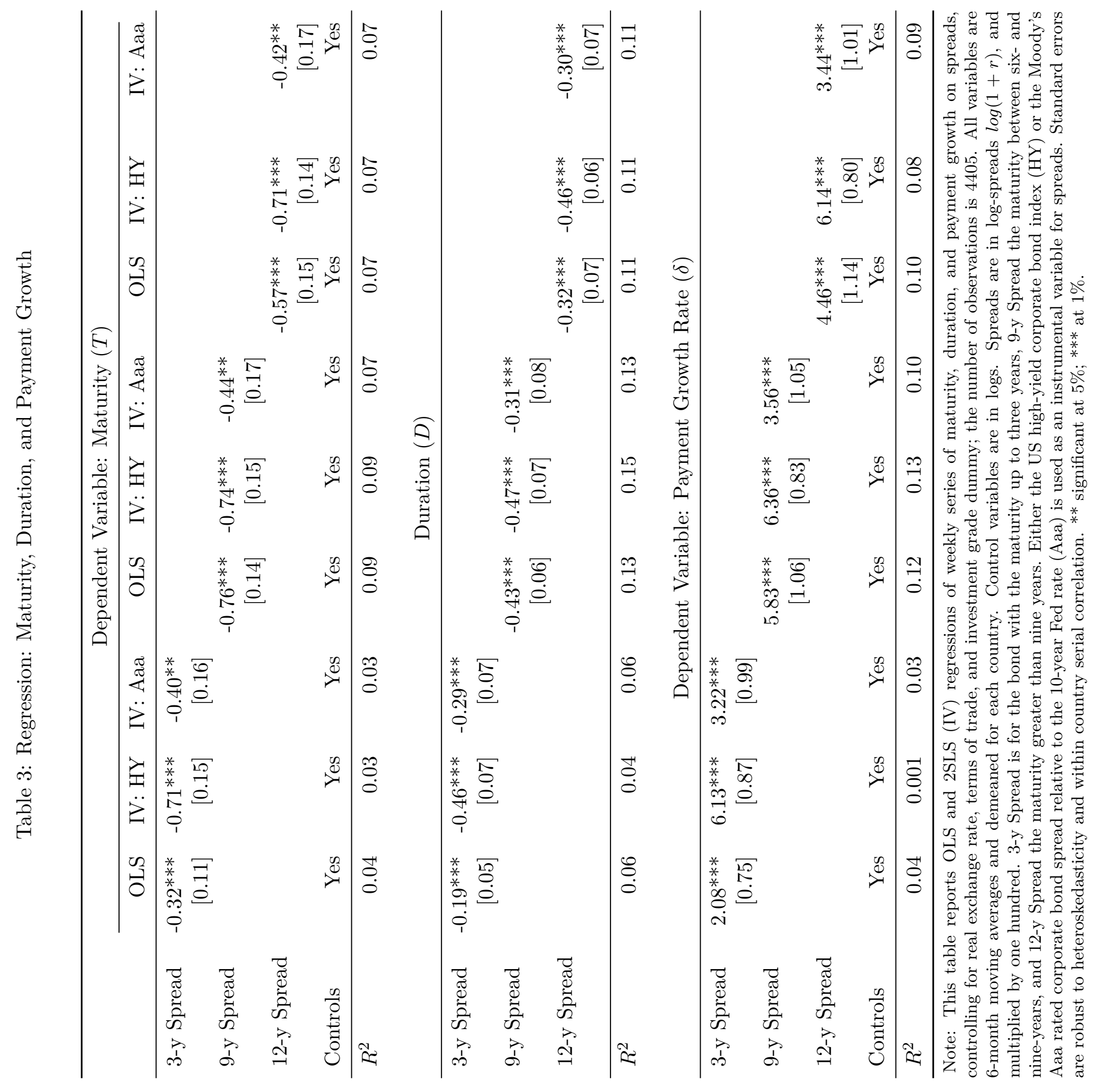


financial distress, by issuing more back-loaded bonds. This has potentially important implications for risk-sharing during downturns and quantitative analyses of long-term debt and maturity choice.

\section{Conclusion}

In this paper we consider a richer description of debt issuance characteristics than previously discussed in the literature, with an emphasis on a measure of back-loading, the growth rate of scheduled payments. In studying the cyclical behavior of this measure, we go beyond the characterization of debt in terms of Macaulay duration and instead consider two complementary measures: payment growth rate and maturity. Using Bloomberg data on the 11 emerging market economies' bond issuance, we find that during recessions and periods of financial distress, countries issue bonds with more back-loaded payments and shorter maturity. Moreover, the observed back-loading is sizable, even conditioning on maturity. Our findings about the countercyclical growth rate of scheduled payments have important implications for risk-sharing during downturns and for the quantitativetheoretic work on long-term debt.

\section{References}

Arellano, C. and A. Ramanarayanan (2012). Default and the maturity structure in sovereign bonds. Journal of Political Economy 120(2), 187-232.

Asonuma, T., D. Niepelt, and R. Ranciere (2017). Sovereign bond prices, haircuts and maturity. IMF Working Paper 17/119, International Monetary Fund.

Broner, F. A., G. Lorenzoni, and S. L. Schmukler (2013). Why do emerging economies borrow short term? Journal of the European Economic Association 11(s1), 67-100.

Chatterjee, S. and B. Eyigungor (2012). Maturity, indebtedness, and default risk. American Economic Review 102(6), 2674-2699.

Hatchondo, J. C. and L. Martinez (2009). Long-duration bonds and sovereign defaults. Journal of International Economics 79(1), 117-125.

Rodrik, D. and A. Velasco (1999). Short-term capital flows. Technical report, National Bureau of Economic Research. 


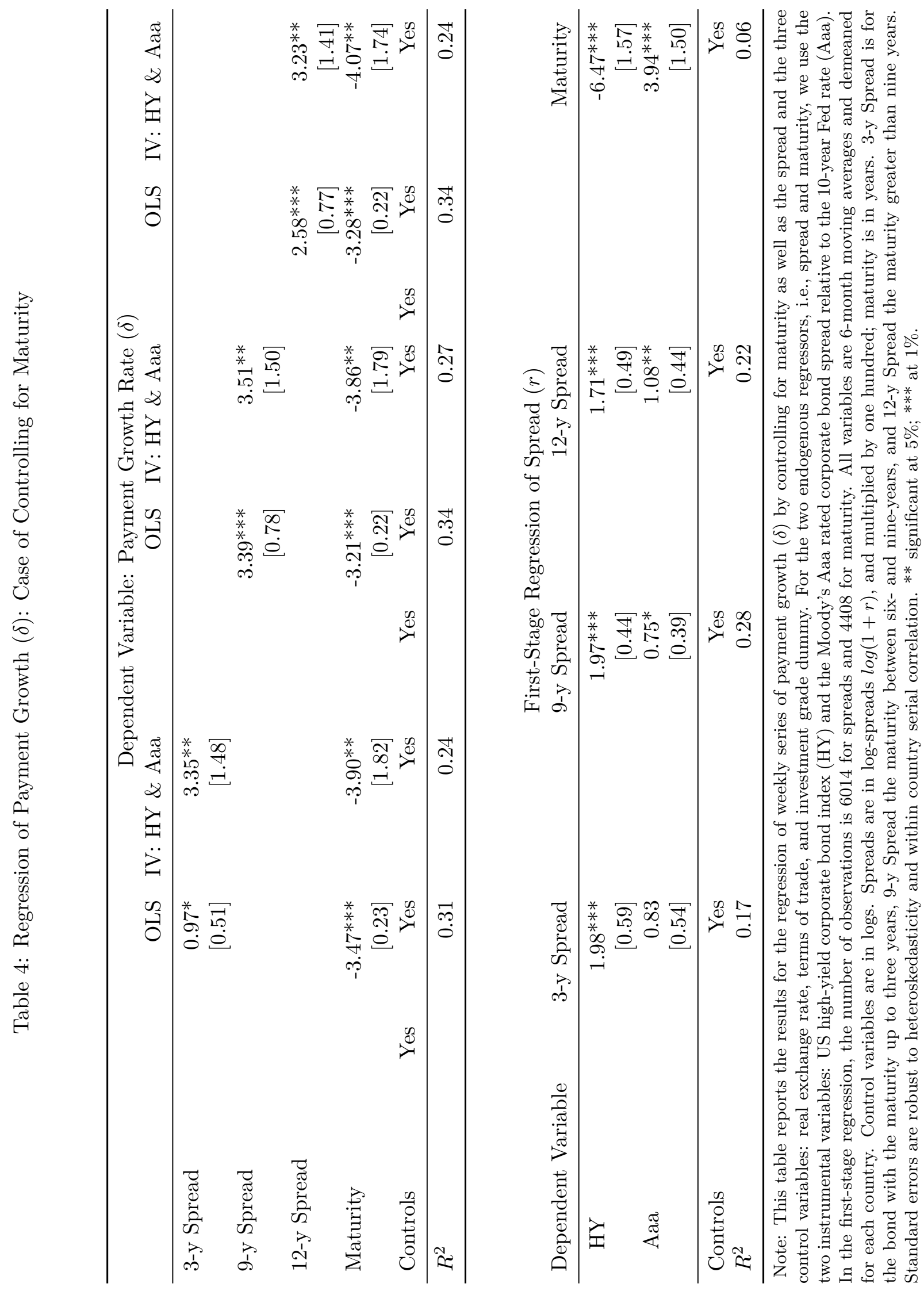

